\title{
Los dos espacios de la pornografía o el conservadurismo paradojal de Susan Sontag
}

\section{The Two Spaces of Pornography or Susan Sontag's Paradoxical Conservatism}

\author{
Nicolás Lema Habash \\ Universidad de París 1 Panthéon-Sorbonne \\ Universidad Bernardo O'Higgins \\ nicolas.lema11@hotmail.com
}

\section{Resumen}

"La imaginación pornográfica" de Susan Sontag (1967) ha sido sindicado como uno de los textos más relevantes sobre pornografía escritos en el siglo xx. También ha sido criticado como excesivamente conservador y elitista. Aquí propongo que el lado conservador de la teoría de la imaginación pornográfica se sustenta implícitamente en la constitución de dos espacios con límites bien definidos, al interior de los cuales se "produce" la pornografía: el espacio social de literatura de alta cultura y el espacio imaginario. La propia restricción del argumento a estos espacios específicos genera una transformación radical de lo que se comprende por pornografía: no es una exposición explícita de lo sexual, sino un saber sobre la muerte. A la vez, constreñir el argumento a estos espacios permite pensar el conservadurismo desde una lógica paradojal, ya que no refiere a los objetos que tradicionalmente se entienden como pornográficos.

Palabras clave: Sontag, pornografía, imaginación pornográfica, conservadurismo, muerte.

\section{Abstract}

Susan Sontag's essay “The Pornographic Imagination” (1967) has been considered as one of the most relevant texts on pornography written in the $20^{\text {th }}$ century. The essay has also been criticized for being excessively conservative and elitist. Here I propose that the conservative aspect of the theory of the pornographic imagination is implicitly based on the constitution of two spaces with well-defined limits, within which pornography is "produced": the social space pertaining to high culture and the space of imagination. The argument's focus on these specific spaces results in the radical transformation of what is understood by pornography: it is not the revealing of sexual explicitness, but a knowledge about death. Focusing the argument on these two spaces allows to consider Sontag's conservatism from a paradoxical perspective, insofar as it does not refer to those objects traditionally understood as pornographic.

Keywords: Sontag, pornography, pornographic imagination, conservatism, death. 
El ensayo "La imaginación pornográfica", de Susan Sontag, publicado originalmente en 1967 en Partisan Review, y luego incluido en el volumen Styles of Radical Will, de 1969, ha sido sindicado como uno de los principales aportes al estudio de la pornografía en el ámbito artístico-literario durante el siglo xx. De hecho, el libro pionero de Linda Williams, Hard Core: Power, Pleasure, and the "frenzy of the Visible", se refiere al ensayo de Sontag como la "vindicación [...] de una pornografía más estética" (10). Asimismo, en su historia de la pornografía titulada El museo secreto, Walter Kendrick anota que el ensayo de Sontag "tuvo un impacto inmediato" luego de haber sido publicado. Sin embargo, Kendrick lanza una crítica radical contra Sontag: la perspectiva de Sontag sobre la pornografía es altamente elitista y, en última instancia, conservadora, al sostener que solo un cierto tipo de literatura pornográfica es digna de ser tomada en serio, a saber, la que pertenece a la alta cultura: "Es una lástima que el elitismo intelectual de Sontag la obligara a concentrar su atención en el estrecho territorio del 'arte', y más específicamente en su recinto literario" (Kendrick 287-288).

La crítica de Kendrick también apuntaba a un hecho más histórico: según este, al momento de escribir "La imaginación pornográfica" — donde Sontag valora una pornografía artística como algo que, según ella, resiste al establishment crítico- el arte ya se había ganado el derecho a representar lo que quisiese, sin importar cuan radical o explícitamente pornográfico fuese. En sí mismo, el ensayo de Sontag no representaría entonces un avance en la lucha contra la censura pornográfica ya que se enfoca en un ámbito específico — el arte- que ya había logrado sacudirse de ella (Kendrick 288-289).

La crítica de Kendrick hace alusión a dos elementos centrales en "La imaginación pornográfica”. En primer lugar, Sontag restringe su estudio a ciertas obras que ella sindica como pornográficas, las que, de hecho, pertenecen a la alta cultura. Estas son obras de literatos tales como Georges Bataille, el Marqués de Sade, o Pauline Réage (seudónimo de Annes Desclos). Podríamos establecer a este ámbito restringido de estudio de la pornografía como "el primer espacio de la pornografía" en el ensayo de Sontag. Este espacio restringido y acotado se refiere a la alta cultura artísticoliteraria. En segundo lugar, Sontag establece otro espacio propio de la pornografía, íntimamente ligado al primero: el espacio imaginario. El título del ensayo, "La imaginación pornográfica”, ya hace alusión implícita a una cierta división entre lo real y lo imaginario. La pornografía de alta cultura expresa un saber único, que pertenece al terreno de lo imaginario, asequible solo a ciertos espíritus artísticos iluminados, pero que no se traduce en acciones concretas en la vida cotidiana. De ahí también el "peligro" de transponer lo que ha sido concebido al nivel del imaginario en el mundo de las acciones prácticas; y de ahí también una cierta inclinación censuradora del ensayo de Sontag respecto de la progresiva masificación de estas obras expresivas de una imaginación pornográfica.

Ambos espacios de la pornografía - el de la alta cultura artística-literaria y el de lo imaginario - conforman lo que podríamos llamar el "conservadurismo" de Sontag. 
Este sería un conservadurismo a nivel social, en la medida en que la pornografía digna de estudio y expresiva de un saber artístico aparece restringida a la creación y recepción de un grupo de personas específicas capaces de llegar a regiones del espíritu a las que la gran mayoría no puede acceder. Pero este es también un tipo de conservadurismo "territorial”: en sí mismo, el objeto "pornografía” está restringido a dos espacios, el artístico-literario y el imaginario, los que forman una suerte de "cerco" que confirma la presencia de una obra digna de calidad.

En este trabajo me propongo caracterizar estos dos espacios de la pornografía en "La imaginación pornográfica". Sin embargo, a partir de esta lectura, me propongo también poner en cuestión el asunto del "conservadurismo" de Sontag. En efecto, sostengo como argumento central que, a pesar de proponer un ámbito de estudio de la pornografía extremadamente acotado a estos dos espacios, no hay nunca en el ensayo de Sontag un afán por censurar la apertura y creación de lo que el sentido común entiende por pornografía, es decir, producciones culturales que contienen un carácter sexual explícito.

Este aspecto es algo que críticas como las de Kendrick no advierten. Al centrarse exclusivamente en el "elitismo" artístico e intelectual de Sontag, ese tipo de ataques a su concepción de la pornografía no advierten que la operación reflexiva de Sontag acerca de la pornografía implica también una subversión de lo que se entiende comúnmente por pornografía. Sorprendentemente, la selección de obras de alta cultura literaria para el estudio de la imaginación pornográfica da cuenta de que para Sontag lo principal en lo que ella entiende por pornografía no está en el hecho sexual, sino en una reflexión sobre la anulación del sujeto o la muerte. El saber que entrega la imaginación pornográfica radica en un saber sobre la muerte y no en un saber sobre el sexo, y es la divulgación de ese saber (el que trabaja sobre la muerte) al cual hace alusión el "peligro" de la divulgación de la pornografía. Para comprender esta noción de pornografía en Sontag será necesario hacer también alusión a algunas de sus notas sobre la noción de artista tout court, y no simplemente del artista que escribe obras pornográficas.

\section{El espacio artístico-literario de la pornografía: más allá del sexo}

Sontag abre "La imaginación pornográfica" estableciendo una diferencia entre los ámbitos en los cuales se ubica la pornografía. Señala que hay al menos tres formas de pornografía: "Por un lado, la pornografía como elemento de la historia social $\mathrm{y}$, por otro, la pornografía como fenómeno psicológico (síntoma de deficiencia o deformidad sexual tanto en los productores como en los consumidores, según la opinión generalizada) y [...] una modalidad o convención menor pero interesante dentro del mundo de las artes" ("La imaginación” 44). Esta diferenciación establece una demarcación entre alta y baja cultura. La pornografía de "calidad" es, a la vez, 
literatura de calidad, a la cual "se aplican las pautas intrínsecas del mérito artístico" (44). Esta apreciación marca la ruta a recorrer por Sontag en su ensayo para desvelar la relevancia y el potencial de lo que llama "imaginación pornográfica”.

Sucede entonces que tras las tres formas de clasificar la pornografía se esconde para Sontag una diferencia respecto de la calidad artística de una obra. En otras palabras, la diferencia entre creaciones pornográficas no radica en el contenido más o menos explícitamente sexual de tal o cual obra, sino en su cualidad artística. Así, la pornografía se delimita como objeto de estudio literario por medio del reconocimiento de una obra en tanto ella ha sido realizada por un auténtico artista, y no por el simple hecho de representar un conjunto de acciones, más o menos explícitas, orientadas a lo sexual.

Aun así, Sontag define una obra pornográfica como un universo totalizador, donde todo se desenvuelve y desarrolla en torno a una situación erótica: "La imaginación pornográfica habita un universo incomparablemente económico, por muy repetitivos que sean los acontecimientos que ocurren en él. Se aplica el criterio de pertinencia más estricto posible: todo debe estar relacionado con la situación erótica" ("La imaginación" 76). La obra expresiva de una imaginación pornográfica "tiene el poder de ingerir, metamorfosear y traducir todas las preocupaciones que le inyectan, rediciéndolo a una sola moneda negociable: la del imperativo erótico. Toda acción se concibe como una serie de intercambios [exchanges] sexuales" (76). El límite de estos intercambios no se restringe a ningún tabú, orientándose siempre potencialmente al infinito, no cerrándose ni siquiera al incesto.

Sin embargo, el texto de Sontag contiene una tensión entre, por una parte, este universo totalizador orientado siempre al intercambio erótico y, por otra, una suerte de telos o quid de la imaginación pornográfica, el que Sontag caracteriza no como el sexo, sino como la muerte. Sontag es explícita a este respecto al comentar la obra de Bataille como uno de los corpus paradigmáticos que expresan la imaginación pornográfica:

Una de las razones por las cuales Histoire de l'oeil y Madame Edwarda producen una impresión tan fuerte y desasosegante [upsetting] estriba en que Bataille entendía, con más claridad que cualquier otro escritor del que yo tenga noticia, que el verdadero objeto de la pornografía [what pornography really is about], no es, en última instancia, el sexo sino la muerte. No sugiero que toda obra pornográfica se ocupe, en términos explícitos o encubiertos, de la muerte. Solo aquellas que abordan esa inflexión específica y más lacerante de los temas lascivos, a saber, 'lo obsceno', lo hacen. Toda búsqueda realmente obscena se encamina hacia las satisfacciones de la muerte, que suceden y sobrepasan a las de eros ("La imaginación" 70, trad. modificada).

En efecto, aunque la obscenidad en Bataille sea un caso particular de pornografía cuyo objeto es la muerte, su caso es probablemente paradigmático, ya que establece una suerte tipo ideal respecto del cual evaluar el quid o el objeto de la pornografía más 
allá del sexo. En efecto, la muerte designa tal vez la forma más radical y explícita de anulación de la personalidad y la subjetividad, en el acontecimiento de devenir cadáver.

Pero el devenir cadáver no es la única forma en que se pueden expresar los límites de la subjetividad y la personalidad humana. Existen otras formas de anulación o autoanulación subjetivas, las que constituyen también en el objeto central de otras obras expresivas de la imaginación pornográfica. Es el caso, por ejemplo, de las novelas Historia de O, de Réage, y Justine, de Sade, obras asiduamente comentadas por Sontag. En ambas, lo que prima es la exploración de la pérdida de la propia personalidad: "En tanto que a Sade le interesa la anulación de la personalidad desde el punto de vista del poder y la libertad, al autor de la Historia de $O$ le interesa la anulación de la personalidad desde el punto de vista de la felicidad" ("La imaginación" 66). La realización de la sexualidad no es entonces un asunto de gratificación placentera y optimista, sino que deviene una extinción del yo: "La mujer a la que no se adjudica más nombre que el de $\mathrm{O}$, progresa simultáneamente hacia su propia extinción como ser humano" (68). En suma, el corpus literario analizado por Sontag rescata, según ella, un fenómeno humano profundo, propio de la sexualidad, pero que sobrepasa a la gratificación erótica: "Por muy domesticada que esté, la sexualidad continúa siendo una de las fuerzas demoníacas de la consciencia humana, que nos empuja esporádicamente hacia los deseos prohibidos y peligrosos, los cuales abarcan desde el impulso a perpetrar un acto súbito de violencia arbitraria contra otra persona, hasta el anhelo voluptuoso de extinguir la propia consciencia, morir literalmente" (67). ${ }^{1}$

Entonces, si bien el universo totalizador de la pornografía se despliega siempre por medio de intercambios erótico-sexuales, estos intercambios no son el fin ni el objeto de la imaginación pornográfica. El espacio artístico-literario de la pornografía genera así una disrupción en el sentido común acerca de la pornografía: la obra pornográfica de excelencia, es decir, aquella que expresa lo que Sontag llama imaginación pornográfica, no supone una gratificación inmediata en términos de placer erótico-sexual (a la manera en que se podría experimentar, por ejemplo, con un juguete sexual), ni para el artista que la crea ni para el lector que la recibe. En lugar de ello, al ser una forma de expresión de un saber, la imaginación pornográfica permite un acceso a los límites de la subjetividad y la consciencia humana. Su objeto es, sino el asunto de devenir cadáver (o materia inorgánica) explícitamente, al menos el de los límites de la subjetividad y personalidad humana, o bien la disolución del "yo".

De hecho, en un ensayo anterior a "La imaginación pornográfica”, titulado "Sobre el estilo”, en momentos en los que al parecer Sontag dudaba aún acerca de si utilizar o no el término "pornografía" para obras de alto vuelo literario, se establece que el asunto de la "anulación del sujeto" es el criterio para establecer lo que luego llamará

1 En toda esta reflexión sobre el erotismo, la muerte y la anulación de yo, Sontag hace, por supuesto, un guiño constante a la reflexión freudiana acerca de la tensión entre la pulsión erótica y la pulsión de muerte, siempre bajo la égida del principio de placer, desarrollada primero en Más allá del principio de placer y luego en El yo y el ello. Un análisis acabado de la relación entre Freud y Sontag va más allá de las posibilidades de este artículo. 
la imaginación pornográfica: en la noción de "la aniquilación del contenido [annihilation of the subject] tenemos quizás el único criterio para distinguir qué literatura, qué cine o qué pintura eróticos serán arte y qué (a falta de una palabra mejor) deberá recibir la denominación de pornografía" ("Sobre el estilo" 44). El término "subject" aquí es ambiguo. En efecto, podría traducirse - como en el pasaje que cito- por "contenido", pero también por "sujeto", lo que implicaría abrir una paleta más amplia de referencias. En este ensayo Sontag claramente se refiere al hecho de que el carácter imaginario de la obra artística rebasa el contenido explícito de lo representado. El criterio de la destrucción del subject en el ámbito del arte erótico se refiere así a que el contenido explícitamente sexual se transfigura en un medio para reflexionar sobre algo más allá del sexo. Sin embargo, leído a la luz de "La imaginación pornográfica", la noción de "anulación del sujeto" resuena con la caracterización de la imaginación pornográfica como la representación de un proceso mediante el cual un personaje pierde progresivamente su "yo" o literalmente deviene cadáver. Ambas interpretaciones de la frase inglesa "annihilation of the subject" dan cuenta de manera precisa de lo que Sontag pretende cuando señala que ahí se encuentra el "criterio" para establecer una distinción dentro de un grupo de obras que representan actos sexualmente explícitos: ora la aniquilación (transfiguración) del contenido explícitamente erótico de la obra, ora la disolución del yo como personalidad individual. ${ }^{2}$

La posibilidad de dotar al universo pornográfico de una capacidad para ir más allá de la simple gratificación sexual inmediata y, en cambio, apuntar a una exploración acerca de la disolución de la subjetividad humana, es justamente lo que diferencia la imaginación pornográfica de la pornografía de consumo masivo. Para Sontag, el sujeto capaz de dotar a una obra pornográfica de esta capacidad exploratoria de los límites de lo humano es el artista. "La imaginación pornográfica" da al artista un rol clave en la producción de una modalidad de consciencia escindida de las demandas de la vida cotidiana. El artista es por consiguiente aquel individuo capaz de traspasar el principio según el cual los intercambios sexuales y eróticos tienen por finalidad la mera satisfacción sexual inmediata. Gracias al artista, la obra pornográfica se transforma: pasa de ser un objeto de satisfacción práctica inmediata, a ser una forma de saber acerca de los límites de la subjetividad.

2 Este no es el caso del uso del término "pornografía" en otras obras posteriores de Sontag. Si bien este no es el espacio para hacer un estudio acabado sobre el devenir de este concepto en todo su trabajo, es importante señalar que en textos justo anteriores a "La imaginación pornográfica", tales como - por ejemplo- los publicados en Contra la interpretación, originalmente aparecido en 1966, la noción de pornografía anuncia ya el asunto de la muerte del sujeto, el que será el objeto central de "La imaginación pornográfica" de 1967. Sin embargo, en Sobre la fotografía (publicado en 1977) y, más específicamente, ya desde el primer ensayo ahí incluido titulado "En la caverna de Platón" (originalmente de 1973), las referencias esparcidas al concepto de pornografía (38-39, 65-66, 108-209) se refieren de manera mucho más estándar a lo que tradicionalmente se entiende como pornografía; es decir, a la escenificación explícita de intercambios sexuales o al ámbito de la obscenidad. Además, en Sobre la fotografía el dilema ético asociado a la pornografía difiere de una reflexión acerca de la anulación del yo. En efecto, Sobre la fotografía se enfoca principalmente en las consecuencias éticas de la difusión masiva de las imágenes en general y, por consiguiente, de la progresiva pérdida del sentido de "shock" o "sorpresa" emocional provocada por la creciente familiaridad con imágenes, tanto de atrocidades como de obscenidades. 
Para lograr esta transformación de la obra pornográfica, el artista utiliza un procedimiento según el cual crea una forma de consciencia extrema, la cual no es exclusiva a la pornografía, sino que es universal a cualquier producción artística. Esta forma de consciencia justamente se materializa en el universo artístico-imaginario de la obra, el que opera en una escala distinta de la vida cotidiana y de sus mecanismos de consciencia codificados socialmente. Por lo mismo, el trabajo del artista puede ser peligroso, ya que, al ir más allá de las exigencias prácticas de la consciencia en la vida cotidiana, se dispone a explorar los límites de esta consciencia, los cuales pueden rozar la locura: "[El] prestigio y autoridad espiritual [del artista] dependen en última instancia de la percepción (sabida o inferida) que el público tenga de las atrocidades que aquel comete contra sí mismo. El artista moderno ejemplar es un traficante de locura [The exemplary modern artist is a broker in madness]" ("La imaginación" 54-55).

En el contexto de una discusión sobre la imaginación pornográfica se podrían entonces señalar dos elementos clave para dar cuenta del rol del artista según Sontag. Primero, el artista, al crear un universo totalizador en términos de intercambios erótico-sexuales, hace devenir este universo en un medio para explorar los límites de la personalidad y la consciencia de la subjetividad humana. La obra expresiva de la imaginación pornográfica no es sobre sexo, como comúnmente se sostiene, sino que es sobre la anulación del yo, gracias al proceder del artista.

Segundo, al realizar esta transfiguración de la obra pornográfica, el artista inscribe la obra en lo que he llamado un "espacio" particular: aquel de la alta esfera cultural artístico-literaria. Por consiguiente, la transformación producida por el artista no solo concierne al contenido de la obra en términos de su objeto central (la muerte, la disolución del yo), sino que también concierne al espacio social en el cual la obra como producto opera. A diferencia de la multiplicidad de documentos destinados a un público masivo, el artista inscribe la obra de imaginación pornográfica en un universo elitista para entendidos capaces de aprehender el sentido de la obra justamente en torno a un devaneo espiritual por los límites de la personalidad humana, en vez de considerarla como objeto de satisfacción sexual inmediata.

Este doble rol del artista, como alguien que transfigura una obra explícitamente sexual en una creación cuyo tema de reflexión es la muerte, y como quien la inscribe dentro de un espacio social de élite, plantea cómo, a pesar de que la imaginación pornográfica implique una forma particular de arte, ella podría ser considerada en efecto como la forma artística ejemplar. En un artículo que aparece en la célebre colección de ensayos Contra la interpretación, Sontag apunta a esta idea cuando escribe a propósito del escritor Cesare Pavese:

El escritor es el sufridor ejemplar, no solo porque haya alcanzado el nivel de sufrimiento más profundo, sino porque ha encontrado una manera profesional de sublimar (en el sentido literal de sublimar, no en el freudiano), su sufrimiento. Como hombre sufre, transforma su sufrimiento en arte. El escritor es el hombre que descubre el uso del sufrimiento en la economía del arte (63) 
El escritor-artista ejemplar no solo transforma el sufrimiento personal en materia para producir una obra, sino que la temática fundamental de la obra que así se produce es justamente una reflexión acerca de la anulación del yo, la cual hace que inevitablemente se enfrente a la muerte. Aun cuando Sontag se refiere a la obra particular de Pavese en este texto, sus declaraciones son generales acerca de la relación entre arte y muerte: "La desinhibida exhibición del egotismo corresponde a la búsqueda heroica de la anulación del yo. [...] La consecuencia final de una concepción del yo así apuntada no podía, al parecer, ser otra que el suicidio" ("El artista” 64).

Sontag dedicó una parte importante de su obra a la reflexión crítica de las múltiples maneras en las que se representa el dolor y el sufrimiento humano. ${ }^{3}$ En el argumento que aquí propongo acerca de la imaginación pornográfica se nos muestra una faceta de este trabajo crítico, al realizarse una suerte de caracterización, no de cualquier representación estética del sufrimiento humano, sino de la que podría ser la manera ejemplar de producir arte: si el artista ejemplar es el que se dedica a producir una reflexión sobre los límites del yo, entonces la pornografía expresiva de la imaginación pornográfica es la obra de arte ejemplar, ya que su tema central siempre será justamente la disolución del sujeto humano. Con esto no estoy sosteniendo que para Sontag solo la imaginación pornográfica constituye la forma de arte ejemplar, sino simplemente que cualquier obra pornográfica digna de formar parte del canon o el espacio del gran arte debe ser también una obra de arte ejemplar. La imaginación pornográfica explora algo que es universal a todo arte, pero lo hace a través de la representación particular de intercambios sexuales ad infinitum.

Efectivamente podemos lanzar una crítica contra el elitismo de Sontag por su conservadurismo en términos de situar a la obra pornográfica dentro de un espacio crítico, artístico y literario particular, marcado por cánones propios de la literatura y el arte culto. Sin embargo, esta crítica debe considerar que a lo que Sontag hace alusión cuando se enfoca en lo que llama la imaginación pornográfica no es al sexo como tal, sino a un problema central del arte: la muerte. Comenzamos así a entender que la restricción de los frutos de la imaginación pornográfica para el gran público no se da en función de una suerte de mojigatería respecto de un supuesto "deber ser" de los comportamientos sexuales de la población en su conjunto, sino por la difusión de un saber que en último término conlleva, según Sontag, un "peligro" para el yo cotidiano de cada subjetividad humana.

3 En este ámbito podemos incluir cuatro de las cinco monografías que Sontag publicó en formato de libros: Trip to Hanoi, Illness as Metaphor, AIDS and Its Metaphors y Regarding the Pain of Others. 


\section{El espacio imaginario de la pornografía: el peligro pornográfico}

La pornografía habita y forma, aparte de un espacio artístico-literario particular, un espacio imaginario. Al ser arte de la más alta calidad, cuyo objeto central es la disolución de la subjetividad humana, la imaginación pornográfica debe mantenerse justamente en el terreno de lo imaginario, separada de la vida cotidiana. Esta separación entre el espacio de lo imaginario y el espacio de lo real-cotidiano en el contexto de una discusión sobre pornografía no se comprende si no se hace alusión a lo que Sontag entiende por arte tout court.

En "Sobre el estilo", Sontag fija parámetros nítidos acerca de la relación entre arte y vida cotidiana. Escribiendo en una línea que podría ser sindicada como heredera de una estética kantiana, donde la experiencia estética se define por el desinterés, Sontag sostiene: "Llegar a implicarse en la obra de arte comporta, sin duda, la experiencia de desprenderse [detanching oneself] del mundo" (46). Manifestándose, al menos en apariencia, contra las tendencias que desde los años 50 y 60 buscaron explícitamente acercar al mundo cotidiano con la esfera del arte, para que este pudiera de hecho intervenir en el plano ético y político, Sontag argumenta abiertamente a favor de una distancia entre el mundo y el arte: “Todas las obras de arte están basadas en una cierta distancia de la realidad vivida que representan. Esta 'distancia' es, por definición, inhumana o impersonal hasta cierto punto; porque para presentarse ante nosotros como arte, la obra debe restringir la intervención sentimental y la participación emocional, que son funciones de 'acercamiento' [closeness]" (48). Sontag define "estilo", justamente como la modalidad específica en que una obra, mediante una serie de convenciones, logra esta distancia entre la realidad humana y su representación artística (48).

Sin embargo, Sontag es consciente respecto de la potencial apatía ética a la cual puede llevar esta idea de obra artística. En el mismo contexto en que establece una separación entre la vida y su representación por parte del arte, Sontag defiende la idea de un cierto feedback de la obra a la vida cotidiana. Aparte de un desprendimiento del mundo, la obra artística puede ser un modo de "nutrir" la consciencia, convirtiéndose en una fuente de enriquecimiento para quien la contempla: "La obra por sí misma resulta también un objeto vibrante, mágico y ejemplar, que nos devuelve al mundo de alguna manera más receptivos y enriquecidos" (46). La obra impacta en el mundo, no mediante una intervención directa en el contenido de su objeto, ni tampoco mediante una serie de directrices morales, las cuales se destinan siempre a la acción pragmática e inmediata. El arte, a diferencia del conocimiento especulativo, nutre la consciencia humana mediante un conocimiento no conceptual. El enriquecimiento que se produce a partir de este conocimiento no tiene ninguna justificación en una acción ulterior, sino que se autojustifica en el conocimiento singular que genera en el sujeto que contempla. El impacto del arte en el mundo es, por consiguiente, indirecto, ya que no pasa por una intervención inmediata en los comportamientos cotidianos, 
sino que lo hace por medio de la absorción de un saber a través de cada consciencia humana desplegada en el mundo ("Sobre el estilo" 47).

Aun cuando en "Sobre el estilo" Sontag no utiliza el término "imaginación" o "imaginario" para definir la esfera de la representación artística, se comprende cómo su concepción de una obra de arte genera la presencia de un espacio único que se deferencia del mundo cotidiano. Este espacio artístico es lo que puede definirse como el espacio de lo "imaginario", el cual se crea con una finalidad contemplativa, y se distancia del mundo cotidiano en la medida en que no está supeditado a los dictados de acciones utilitarias y pragmáticas. Así se comprende cómo a partir de esta concepción de arte se define a la pornografía de alto vuelo artístico-literario como expresiva justamente de una imaginación pornográfica. Las grandes obras pornográficas, tal como las creadas por Bataille o Sade, establecen un espacio específico gracias a su objeto de reflexión (los límites de la subjetividad humana), pero también lo hacen en un espacio particular, aquel de "lo imaginario".

Ya en "Sobre el estilo" Sontag deslizaba que la obra de arte se diferenciaba de la pornografía (no expresiva de una imaginación pornográfica), en la medida en que el arte se aleja de las exigencias emocionales del mundo cotidiano. La pornografía buscaba excitar y, por consiguiente, se convierte, a la manera de un juguete sexual, "en un sucedáneo de la vida" (44). En cambio, "el arte no excita; o si lo hace, la excitación se apacigua dentro de los términos de la experiencia estética” (44). El espacio imaginario que induce a la contemplación estética genera que la obra de arte pornográfica no sea pornografía tout court, sino que la dota de herramientas propias del arte que la sacan de la esfera animal de la excitación inmediata y de la esfera pragmática de su "uso" como "artefacto" erótico. Dicho de otro modo, el hecho de que la obra expresiva de imaginación pornográfica no sea un juguete sexual se da justamente gracias a que ella se manifiesta en un espacio separado de la realidad mundana inmediata.

A partir de estas consideraciones se entienden algunas de las ideas centrales vertidas en "La imaginación pornográfica" respecto de la separación entre vida y obra artística pornográfica. Esta separación se refleja en dos conceptos que Sontag utiliza para dar cuenta de la operación específica realizada por la imaginación pornográfica: los conceptos de "existencia humana" y "existencia sexual". Si la exploración de los límites de la propia personalidad y la humanidad en obras que despliegan una radical imaginación pornográfica se da por medio de la potencialización, en el terreno artístico, de la pulsión sexual, ello puede ocurrir en estas obras justamente porque lo que ahí se realiza es una escisión entre una "existencia humana" y una "existencia sexual": Lo que la literatura pornográfica

hace es ni más ni menos que insertar una cuña entre nuestra existencia como seres humanos cabales y nuestra existencia como seres humanos sexuales, en tanto que en la vida corriente el individuo sano es el que impide que se abra esta brecha. Normalmente no experimentamos, o por lo menos no queremos experimentar, nuestra realización sexual como algo distinto de nuestra realización personal, u opuesto a ella ("La imaginación” 68). 
La noción de existencia humana se refiere a las acciones que el animal humano realiza en su vida cotidiana, en el mundo pragmático, donde debe convivir en sociedad con otros seres humanos. En esta esfera, dice Sontag, la sexualidad se vive justamente como la realización de la propia subjetividad, es decir, en armonía con una serie de otras obligaciones morales propias del animal humano. Lo interesante aquí es que esta vivencia de la sexualidad como parte de una existencia plenamente humana fortifica la experiencia de un "yo" (self) como sujeto en posesión de sí mismo ("La imaginación" 68-69).

Romper con esta existencia humana implica poner en evidencia una serie de impulsos ligados a la sexualidad que, como ya se ha esbozado más arriba, deben ser domesticados porque ellos llevan inexorablemente a violencia, crueldad y autodestrucción. Utilizando a Friedrich Nietzsche como autor guía, Sontag sostiene que la existencia sexual siempre se encuentra en estado de latencia en el sujeto humano, pero que ella no sale a la luz durante la existencia humana cotidiana debido a una serie de mecanismos de control a nivel moral, social y cultural ("La imaginación" 67-68). En efecto, el desencadenamiento radical de esta existencia sexual sería fatídica para la existencia del animal humano, ya que su despliegue implicaría que la sexualidad ya no se vive como coextensiva con la realización de la personalidad individual, sino justamente como una pérdida del yo. Así, Sontag establece que la "sanidad" en la esfera de la vida humana cotidiana depende justamente de mantener a la existencia sexual en línea con la existencia humana, lo cual implica, obviamente, establecer límites a la existencia sexual: "Se podría argüir plausiblemente que existen muy buenas razones para que la mayoría de las personas no tengan acceso a la capacidad máxima de éxtasis sexual, dado que la sexualidad, como la energía nuclear, tal vez sea susceptible de subordinarse a los escrúpulos, y tal vez no lo sea" ("La imaginación" 67).

La literatura pornográfica analizada por Sontag logra explorar los límites de la experiencia humana, adentrándose en las más recónditas actividades de la existencia sexual. Pero lo hace en el espacio de lo imaginario, manteniendo así a raya el despliegue de la existencia sexual dentro del campo de la representación artística, es decir, dentro del campo de la "imaginación" pornográfica. Es solamente en este campo en donde se puede generar aquel universo "totalizador" de intercambios sexuales al infinito. En el caso de que esto se realizara en la esfera de las acciones humanas en la vida cotidiana, ello iría en detrimento de la "sanidad" del animal humano. Por lo mismo, el artista, como se ha señalado, toca la locura al explorar esta existencia sexual, no porque él mismo lleve a cabo estos actos en su existencia cotidiana, sino porque su consciencia se adentra en un espacio imaginario que, para Sontag, inevitablemente lo aproxima a la disolución de su yo.

Por consiguiente, podemos distinguir dos aspectos de "conservadurismo" de Sontag respecto del espacio imaginario de la pornografía. Por una parte, hay un aspecto que podríamos llamar "ontológico" respecto de la relación entre lo imaginario y la pornografía: es parte del "ser" de la obra expresiva de la imaginación pornográfica 
el pertenecer a un espacio imaginario; no podría ser de otra manera, ya que lo que la imaginación pornográfica representa (aquel universo erótico totalizante) no podría ser experimentado en una vida humana cotidiana, en la medida en que implicaría la destrucción del yo. La exploración de este ámbito de radical existencia sexual se da así en la esfera desinteresada y desconectada del mundo que conforma la obra de arte, cuya finalidad no es ser modelo de acción, sino alimento para la consciencia. Por otra parte, Sontag introduce un aspecto que podríamos caracterizar como "axiológico": no solo le compete al ser de la existencia sexual el delimitarse al espacio de la imaginación, sino que es importante evitar que esta existencia sexual, representada en la obra artística pornográfica, se desparrame fuera de los límites del arte y de las consciencias de aquellos y aquellas que estén capacitados para recibirla. A ello justamente es a lo que Sontag se refiere cuando habla, hacia el final de su ensayo de la relativa "calidad del sujeto humano" para recibir y absorber el conocimiento que la imaginación pornográfica entrega: "El problema no gira en torno de la existencia de la consciencia o del conocimiento, sino a la calidad de la consciencia y del conocimiento. Y esto invita a meditar sobre la calidad o el refinamiento del sujeto humano [fitness of the subject], el más problemático de los estándares (83, trad. modificada).

Este aspecto altamente paternalista de la reflexión de Sontag da cuenta de un conservadurismo, no respecto de la pornografía en particular como medio de representación de prácticas sexuales, sino de una forma de saber no conceptual que, según ella, pone en peligro los límites dentro de los cuales la existencia humana se mantiene sana y vivible. Si antes señalé que el conservadurismo de Sontag respecto de la caracterización del espacio artístico-literario de la pornografía no se expresa en una mojigatería respecto de los intercambios sexuales, sino por el hecho de que la pornografía trata sobre los límites de la subjetividad humana, esta aserción ahora se complementa con que Sontag no intenta delimitar la pornografía a un espacio imaginario con el fin de anular la experimentación sexual en la vida cotidiana. En la medida en que el objeto de la imaginación pornográfica trata sobre la disolución del yo, el riesgo de que la representación pornográfica se escape del espacio imaginario no radica en la experimentación con el placer sexual, sino en la disolución violenta de la existencia humana.

\section{Los espacios implícitos de la pornografía o las paradojas del conservadurismo}

Sostengo que el conservadurismo de Sontag es paradojal _inspirándome en la concepción que titula el célebre libro de François Zourabichvili, Le conservatisme paradoxal de Spinoza - ya que al restringir de tal manera su campo de estudio sobre la pornografía, ella restringe también los objetos respecto de los cuales es "conservadora", en el sentido de mantenerlos alejados del público masivo. Al limitar unos espacios 
donde se produce lo que llama imaginación pornográfica, Sontag consigue modificar de manera sustancial lo que se entiende por pornografía según el sentido común. Asimismo, al aislar unas obras específicas donde se produce la llamada imaginación pornográfica, deja libre de su estudio (y también de sus preocupaciones acerca de los "peligros" que pueden conllevar) una serie de otras instancias donde se representa lo que comúnmente se entiende por pornografía, es decir, una serie de documentos y obras donde lo que prima es la representación de lo sexualmente explícito.

Al restringir el ámbito de estudio de la pornografía a un espacio artístico-literario y a un espacio imaginario, Sontag no se pronuncia respecto de los peligros, las modalidades y la relevancia sociocultural de las "otras" pornografías de las cuales Sontag reconoce su existencia, pero que no analiza. Paradojalmente, el conservadurismo de Sontag se aplica solamente a un ámbito de la pornografía que comprende las representaciones de la imaginación pornográfica, cuyo objeto central, como se ha explicado a lo largo de este artículo, no es el sexo, sino los límites de la subjetividad humana o la muerte. En la medida en que su argumento se restringe solo a este corpus particular, no es posible decir que Sontag sea conservadora respecto de la difusión y uso de las otras formas de pornografía que no se enmarcan en los dos espacios que ella le otorga a la imaginación pornográfica.

Esta interpretación está sujeta a críticas especialmente porque, para defenderla, estoy explotando un silencio en la obra de Sontag; es decir, estoy explotando justamente el hecho de que ella no se refiere (aparte de nombrarlos en el párrafo introductorio de "La imaginación pornográfica") a otros documentos y obras de naturaleza pornográfica. Más aún, en uno de sus pasajes más polémicos, "La imaginación pornográfica" utiliza ambiguamente el término "pornografía", sin explicar si ello refiere a obras de altos estándares literarios o bien si se refiere a representaciones que se encuentran fuera del ámbito de la imaginación pornográfica:

“Qué cabe decir, empero, a las muchas personas sensatas y sensibles que consideran deprimente el hecho de que en los últimos años se haya puesto al alcance de los muy jóvenes toda una biblioteca de materiales de lectura pornográficos, en ediciones de bolsillo? Probablemente cabe decirles lo siguiente: que su preocupación está justificada, aunque tal vez sea desproporcionada. No me dirijo a los quejosos crónicos, a aquellos que opinan que puesto que el sexo es al fin y al cabo procaz [dirty], también lo son los libros que se regodean con él [are revealing of sex] [...]. Pero aún existe una apreciable minoría que objeta la pornografía o le tiene repulsión no porque la crea procaz [dirty] sino porque sabe que puede ser un arma para las personas que sufren aberraciones psíquicas y un medio para envilecer a los moralmente inocentes. Yo también tengo aversión a la pornografía por estas razones, y me inquietan las consecuencias de su creciente difusión. ¿Pero la preocupación no está un poco descaminada? ¿Qué es lo que está verdaderamente en juego? La preocupación por los usos del conocimiento. En cierto sentido todo conocimiento es peligroso, porque no 
todas las personas se encuentran en las mismas condiciones como conocedoras reales o potenciales. Quizá la mayoría de las personas no necesitan 'una escala de experiencias más vasta”" ("La imaginación 81-82).

En este pasaje, donde Sontag habla explícitamente sobre el peligro de la pornografía y, consecuentemente, de la necesidad por restringir el acceso a la "pornografía", ¿qué quiere decir "pornografía”?

Una serie de elementos nos invitan a interpretar que a lo que Sontag se refiere aquí por pornografía es el mismo corpus al cual había estado haciendo alusión durante todo su ensayo, es decir, a una modalidad artística de alto vuelo literario, cuyo objeto no es el sexo, sino la muerte. Primero, la última sección del ensayo, de la cual forma parte este citado pasaje, continúa restringiendo el campo de estudio a la "pornografía, considerada como forma artística, o productora de arte, de la imaginación humana” (81). Segundo, en el propio pasaje recién citado Sontag sostiene que lo potencialmente peligroso no es el sexo per se, sino la forma de conocimiento no conceptual que provee una obra de arte; y, como se sostiene, este conocimiento no se encuentra en documentos u obras cuyo fin es simplemente excitar sexualmente a su consumidor (nuevamente, a la manera de un juguete sexual), sino que se localiza en obras artísticas de alta cultura. Si Sontag estuviera hablando de documentos pornográficos no artísticos, ni siquiera podría hacer alusión a una apertura de la consciencia, ya que esto solo puede producirse gracias al conocimiento vertido por un artista en una obra de arte.

Por consiguiente, la preocupación de Sontag acerca del consumo de pornografía y, por ende, sus guiños a ciertos mecanismos de censura, se restringen al espacio de la imaginación pornográfica, que es fuente de conocimiento. Esta actitud conservadora debe ser temperada también en la medida en que, incluso cuando se refiere a la imaginación pornográfica, Sontag sostiene implícitamente la posibilidad de que potencialmente, con "una preparación psicológica sutil y de gran magnitud" (82) previa, sí es posible la apertura progresiva de estas obras a un público cada vez mayor. El conservadurismo de Sontag se basa, en efecto, en una actitud elitista respecto del conocimiento que entregan las creaciones artístico-culturales (o al menos algunas de ellas), las cuales pueden interferir en la sanidad del común de la población. Sin embargo, es de destacar que este conservadurismo se refiere a un conjunto de obras extremadamente restringido, cuyo consumo debe estar mediado por un proceso, en último término, de educación, es decir, de preparación intelectual para poder comprender el conocimiento que entregan estas obras.

Si mi argumento hasta aquí es correcto, entonces nada en "La imaginación pornográfica" esboza mecanismos de censura para lo que corrientemente se entiende por pornografía, es decir, aquellos documentos tales como los filmes hardcore que incitan a la excitación sexual del espectador. Puede que Sontag sea elitista en el sentido de restringir su campo de análisis a la alta cultura artístico-literaria; pero es esta misma 
restricción, esta misma delimitación de los espacios propios de esta pornografía, la que permite establecer que para ella el asunto de la producción, difusión y consumo de obras sexualmente explícitas no tiene nada de peligroso en sí mismo, al menos en el marco de la discusión de "La imaginación pornográfica". Si lo peligroso es el conocimiento que otorgan las obras expresivas de imaginación pornográfica, estas otras obras simplemente no contienen ningún conocimiento particular y se acoplan al quehacer mundano como "sucedáneos de la vida" (44).

Dicho de manera más explícita: ¿Debe ser censurada una obra cinematográfica hardcore como, por ejemplo, Behind the Green Door (Detrás de la puerta verde, 1972), uno de los filmes icono de la pornografía durante los años 70? Según el argumento que estoy proponiendo acerca de Sontag, una obra como Detrás de la puerta verde no cumple una función distinta de un juguete sexual: su fin es excitar al espectador mediante una serie de escenas visuales que representan actos sexuales explícitos. A diferencia de las obras de Sade o Bataille, su objeto no son los límites de la consciencia humana. Por consiguiente, Detrás de la puerta verde no transmite ningún conocimiento acerca de la "existencia sexual" del ser humano, sino que se mantiene en línea con la "existencia humana", es decir, en la esfera pragmática de la acción y no en el espacio imaginario propio del conocimiento artístico no conceptual. El aporte cultural de Detrás de la puerta verde puede que sea así considerado como banal y, en el límite, como indigno de un estudio crítico; pero nada de esto quiere decir que haya necesidad de restringir su acceso por parte del público masivo. ${ }^{4}$

\section{Referencias}

Freud, Sigmund. Más allá del principio de placer. Trad. José L. Etcheverry. Obras completas, vol. xviII. Amorrortu, Buenos Aires, 1979.

- - El yo y el ello. Trad. José L. Etcheverry. Obras completas, vol. XIX. Amorrortu, Buenos Aires, 1979.

Kendrick, Walter. El museo secreto. La pornografía en la cultura moderna. Trad. Eduardo Jaramillo-Zuluaga. Bogotá, Tercer Mundo, 1995.

Sontag, Susan. “The Pornographic Imagination”. Partisan Review 34 (1967).

-—. Trip to Hanoi. Nueva York, Farrar, Straus \& Giroux, 1968.

4 Como señalé más arriba a propósito de Sobre la fotografía, la discusión en torno a la difusión masiva de imágenes pornográficas será retomada en este libro con otros matices, como parte de una problematización mayor en torno al asunto de la progresiva familiarización con lo que las imágenes muestran. Cabe señalar que, cuando me refiero a la potencial "censura" o al "peligro" de la difusión de obras pornográficas, lo hago en este artículo exclusivamente respecto del argumento de Sontag en "La imaginación pornográfica". Por consiguiente, nada de lo que se señala en esta conclusión implica que la pornografía hardcore no pueda ser considerada "censurable" (o incluso "peligrosa") desde otras perspectivas, o que sus implicancias ético-políticas acerca de la escenificación de los géneros y los sexos puedan conllevar violencia respecto de cómo ellos ahí se representan. Una tal crítica política sobre la pornografía ha sido ya ampliamente tematizada por la literatura feminista, pero aquella discusión no aparece explícitamente en Sontag. 
-—. "Sobre el estilo". Trad. Javier González-Pueyo. Contra la interpretación. Barcelona, Seix Barral, 1969.

- - . "El artista como sufridor ejemplar". Trad. Javier González-Pueyo. Contra la interpretación. Barcelona, Seix Barral, 1969.

-_. Illness as Metaphor. Nueva York: Farrar, Straus \& Giroux, 1978.

- - "La imaginación pornográfica". Trad. Eduardo Goligorsky. Estilos radicales: Ensayos. Barcelona, Muchnik Editores, 1985.

-_. AIDS and Its Metaphors. Londres, Allen Lane, 1989.

- - Regarding the Pain of Others. Nueva York, Farrar, Straus \& Giroux, 2003.

- - "Sobre el estilo". Trad. Javier González-Pueyo. Contra la interpretación. Barcelona, Seix Barral, 1969.

- - Sobre la fotografía. Trad. Carlos Gardini. México, Alfaguara, 2006.

Williams, Linda. Hard Core: Power, Pleasure, and the "Frenzy of the Visible". Berkeley, University of California Press, 1989. 